\title{
Inovasi Pembelajaran Pendidikan Agama Islam Berbasis Problem Based Learning
}

\author{
Ikrima Mailani \\ Universitas Islam Kuantan Singingi Teluk Kuantan, Indonesia
}

\begin{abstract}
Article Info
Article history:

Received Oct $10^{\text {th }}, 2018$

Revised Jan 10 ${ }^{\text {th }}, 2019$

Accepted Jan 12th, 2019

\section{Keyword:}

Innovation

Problem based learning

Islamic education

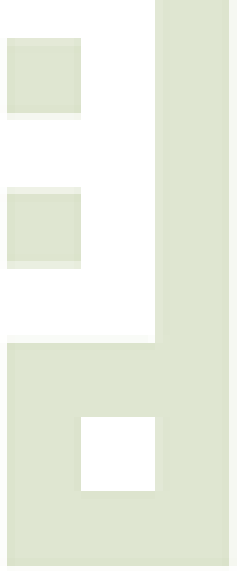

\section{ABSTRACT}

Educators are very important in their efforts to achieve the desired learning goals in the activities of the teaching and learning process. While students act as subjects as well as objects in applying strategies, models and learning methods. Various ways can be done by the teacher/lecturer to be able to convey information to students (knowledge transfer), both in the form of learning related to teaching materials or insightful ones globally. The process of transferring knowledge with the classical/traditional method can no longer be maintained, because students who are expected by the community are intelligent students who are responsive to the development of the times, and not just as spectators and listeners. The breakthrough offered by observers of education is with a new concept, namely the Problem Based Learning (PBL) learning model, this learning model is not just a process of transferring knowledge from teacher to student, but students can do, try and reconstruct their own teaching materials based on problems existing in the educational environment. Changing the old paradigm that states that every problem must be avoided, but changing it into a new paradigm, that a problem must be faced and the solution sought as soon as possible, so also in the process of teaching and learning activities that give birth to effective, creative and innovative learning.
\end{abstract}

Copyright (C) 2018, AL-USWAH. All rights reserved.

\section{Corresponding Author:}

\section{Ikrima Mailani}

Universitas Islam Kuantan Singingi Teluk Kuantan, Indonesia

Email: ikrimamailani@gmail.com 


\section{PENDAHULUAN}

Undang Undang tentang Sistem Pendidikan Nasional menjelaskan proses pembelajaran pada satuan pendidikan diselenggarakan secara interaktif, inspiratif, menyenangkan, menantang, memotivasi peserta pidik untuk berpartisipasi aktif, serta memberikan ruang yang cukup bagi prakarsa, kreativitas, dan kemandirian sesuai dengan bakat, minat dan perkembangan fisik serta psikologis peserta didik. ${ }^{1}$

Model pembelajaran terus berkembang sebagai usaha untuk meningkatkan kualitas pendidikan dan kualitas pembelajaran. Kemampuan guru dituntut untuk selalu melakukan pembaharuan pada setiap pembelajaran karena akan mempengaruhi hasil belajar siswa. Banyak model pembelajaran yang menekankan pada keaktifan siswa di dalam proses pembelajaran, di antaranya adalah problem based learning (PBL), based internet, dan pictorial riddle. Jika akan menggunakan pendekatan student center, maka model pembelajaran problem based learning bisa digunakan oleh guru untuk mengaktifkan siswa di kelas tersebut. Istilah problem based learning sebenarnya sudah tidak asing lagi dalam dunia pendidikan, akan tetapi yang jadi permasalahan adalah ketika mengaplikasikannya pada pembelajaran Pendidikan Agama Islam.

Dalam menjalankan tugasnya seorang guru setidaknya harus

1 Peraturan Pemerintah Republik Indonesia Nomor 32 Tabun 2013. memiliki kemampuan dan sikap, antara lain menguasai kurikulum, menguasai substansi materi yang diajarkannya, menguasai metode dan evaluasi belajar (guru harus memilih metode apa yang cocok untuk suatu mata pelajaran, dan metode lainya dapat digunakan atau sesuai dengan mata pelajaran lainnya), tanggung jawab terhadap tugas, dan disiplin dalam arti luas. ${ }^{2}$

Dalam proses belajar mengajar unsur guru dan anak didik harus bisa aktif. Aktif dalam arti baik dari segi sikap, mental maupun perbuatan. Dalam proses sistem pengajaran harus melalui sebuah pendekatan keterampilan kegiatan proses belajar mengajar, di mana anak didik harus lebih aktif dari pada guru. Guru mestinya hanya bertindak sebagai pembimbing dan fasilitator saja. Sehingga dalam proses belajarmengajar bisa bersifat dialogis/aktif. ${ }^{3}$

\section{DEFINISI PROBLEM BASED LEARNING (PBL) DAN PERKEMBANGANNYA}

Pembelajaran berbasis masalah adalah proses pembelajaran yang menggunakan pendekatan sistematik untuk memecahkan masalah atau menghadapi tantangan yang akan diperlukan dalam kehidupan nyata. Proses pembelajaran diarahkan agar

${ }^{2}$ Binti Maunah, Landasan Pendidikan (Yogyakarta: Teras, 2009), 151-152

${ }^{3}$ Nurfuadi, Profesionalisme Guru (Purwokerto: STAIN Press, 2012), 73 
siswa mampu menyelesaikan masalah secara sistematis.

Perkembangan siswa tidak hanya terjadi pada aspek kognitif, tetapi juga aspek afektif dan psikomotor melalui penghayatan secara internal akan problema yang dihadapi seperti yang dikutip oleh Sutriman dari Sanjaya. Dengan demikian, pembelajaran berbasis masalah merupakan model pembelajaran yang berangkat dari pemahaman siswa tentang suatu masalah, menemukan alternatif solusi atas masalah, kemudian memilih solusi yang tepat untuk digunakan dalam memecahkan masalah tersebut. ${ }^{4}$

Problem based learning memiliki ciri-ciri, seperti pembelajaran dimulai dengan pemberian masalah, biasanya masalah memiliki konteks dengan dunia nyata, pembelajar secara berkelompok aktif merumuskan masalah dan mengidentifikasi kesenjangan pengetahuan mereka, mempelajari dan mencari sendiri materi yang terkait dengan masalah, dan melaporkan solusi dan masalah. Sementara pendidik lebih banyak memfasilitasi. Ketimbang memberikan kuliah, ia merancang sebuah skenario masalah, memberikan clue indikasi-indikasi tentang sumber bacaan tambahan dan berbagai arahan dan sasaran yang diperlukan. ${ }^{5}$ Dilihat dari aspek psikologi belajar,

${ }^{4}$ Sutirman, Media dan Model-Model Pembelajaran Inovatif (Yogyakarta: Graha Ilmu, 2013), Cet. Pertama, 39.

${ }^{5} \mathrm{M}$. Taufiq Amir, Inovasi Pendidikan Melalui Problem Based Learning (Jakarta: Kencana, t.th.), Cet. Pertama, 12 strategi pembelajaran berbasis masalah bersandarkan kepada psikologi kognitif yang berangkat dari asumsi bahwa belajar adalah proses perubahan tingkah laku berkat adanya pengalaman. Belajar bukan semata-mata proses menghafal sejumlah fakta, tetapi suatu interaksi secara sadar antara individu dengan lingkungannya. Melalui proses ini sedikit demi sedikit siswa akan berkembang secara utuh, artinya, perkembangan siswa tidak hanya terjadi pada aspek kognitif, tetapi juga aspek afektif dan psikomotorik melalui penghayatan secara internal akan problema yang dihadapi. ${ }^{6}$

\section{KARAKTERISTIK DALAM PROBLEM BASED LEARNING}

Sebagai model pembelajaran tentunya problem based learning memiliki karakteristik di antaranya:

a. Masalah digunakan sebagai awal pembelajaran.

b. Biasanya, masalah yang digunakan merupakan masalah dunia nyata yang disajikan secara mengambang.

c. Masalah biasanya menuntut perspektif majemuk (multiple perspektive). Solusinya menuntut pembelajar menggunakan dan mendapatkan konsep dari beberapa bab perkuliahan (atau SAP) atau lintas ilmu ke bidang lainya.

d. Masalah membuat pembelajar tertantang untuk mendapatkan

Wina Sanjaya, Strategi Pembelajaran (Jakarta: Kencana, 2006), Cet. I, 213-214 
pembelajaran di ranah pembelajaran yang baru.

e. Sangat mengutamakan belajar mandiri (self directed learning).

f. Memanfaatkan sumber pengetahuan yang bervariasi, tidak dari satu sumber saja. Pencarian, evaluasi serta penggunaan pengetahuan ini menjadi kunci penting.

g. Pembelajarannya, kolaboratif, komunikatif, dan kooperatif. Pembelajar bekerja dalam kelompok, berinteraksi, saling mengajarkan (peer teaching), dan melakukan presentasi. ${ }^{7}$

Sedangkan berdasarkan teori yang dikembangkan Barrow, Min Liu, sebagaimana dikutip oleh Aris menjelaskan lima karakteristik $P B L$ yang meliputi:

a. Learning is student-centered, proses pembelajaran dalam PBL lebih menitikberatkan kepada siswa sebagai orang belajar. Oleh karena itu, PBL didukung juga oleh teori kontruktivisme dimana siswa di dorong untuk dapat mengembangkan pengetahuannya sendiri.

b. Authentic problem form the organizing focus for learning, masalah yang disajikan kepada siswa adalah masalah yang otentik sehingga siswa mampu dengan mudah memahami masalah tersebut serta dapat menerapkannya dalam kehidupan profesionalnya nanti.

c. New information is acquired through self-directed learning, dalam proses

${ }^{7}$ M. Taufiq Amir, Inovasi Pendidikan..., 22 pemecahan masalah mungkin saja siswa belum mengetahui dan memahami semua pengetahuan prasyaratnya sehingga siswa berusaha untuk mencari sendiri melalui sumbernya, baik dari buku atau informasi lainnya.

d. Learning occurs in small groups, agar terjadi interaksi ilmiah dan tukar pemikiran dalam usaha membangun pengetahuan secara kolaboratif, PBM/PBL dilaksanakan dalam kelompok kecil. Kelompok yang dibuat menuntut pembagian tugas yang jelas.

e. Teachers act as facilitators, pada pelaksanaan $P B L$, guru hanya berperan sebagai fasilitator. Meskipun begitu guru harus selalu memantau perkembangan aktivitas siswa dan mendorong mereka agar mencapai target yang hendak dicapai. ${ }^{8}$

Untuk mengimplementasikan model pembelajaran berbasis masalah, guru perlu memilih bahan pelajaran yang memiliki permasalahan yang dapat dipecahkan. Permasalahan tersebut bisa diambil dari buku teks atau dari sumbersumber lain misalnya dari peristiwa yang terjadi di lingkungan sekitar, dari peristiwa dalam keluarga atau dari peristiwa kemasyarakatan. ${ }^{9}$

${ }^{8}$ Aris Shoimin, 68 Model Pembelajaran Inovatif dalam Kurikulum 2013 (Yogyakarta: ArRuzz Media, 2014), 130

'Wina Sanjaya, Strategi Pembelajaran..., 214-215 
Menurut Amir, ${ }^{10}$ landasan teori PBL adalah kontruktivis. Pada model ini pembelajaran dimulai dengan menyajikan masalah nyata yang penyelesaiannya membutuhkan kerjasama antara siswa, guru memandu siswa menguraikan rencana pemecahan masalah menjadi tahaptahap kegiatan, guru memberi contoh mengenai penggunaan keterampilan dan strategi yang dibutuhkan supaya tugas-tugas tersebut dapat diselesaikan. Guru menciptakan suasana kelas yang fleksibel berorientasi pada upaya penyelidikan siswa.

Pembelajaran PBL merupakan model belajar yang menggunakan masalah sebagai langkah awal dalam mengumpulkan dan mengintegrasikan pengetahuan baru. Model ini juga berfokus pada keaktifan peserta didik dalam kegiatan pembelajaran, siswa tidak lagi belajar satu arah seperti pada model pembelajaran konvensional. Dengan model pembelajaran ini diharapkan siswa dapat mengembangkan pengetahuan mereka sendiri. PBL memiliki ciri-ciri seperti yang dikemukakan Amir ${ }^{11}$ "pembelajaran dimulai dengan pemberian masalah, biasanya memiliki konteks dengan dunia nyata, pembelajar secara berkelompok aktif merumuskan masalah dan mengidentifikasi kesenjangan pengetahuan mereka, mempelajari dan mencari solusi dari masalah. Sementara pendidik lebih banyak memfasilitasi. Ketimbang memberi materi, 11

10M. Taufiq Amir, Inovasi Pendidikan...,

11Ibid., 12 pendidik merancang sebuah sekenario masalah, memberikan clue indikasi-indikasi tentang sumber bacaan tambahan dan berbagai arahan dan saran yang diperlukan saat pelajar menjalankan proses. Meskipun bukanlah pembelajaran yang sama sekali baru, menyatakan bahwa penerapan model pembelajaran PBL mengalami kemajuan yang pesat di banyak sekolah dari disiplin ilmu di negara-negara maju. ${ }^{12}$

Pembelajaran berbasis masalah mempunyai 5 asumsi utama, yaitu: ${ }^{13}$

a. Pembelajaran bersifat student centered

b. Pembelajajaran terjadi pada kelompok-kelompok kecil

c. Guru berperan sebagai fasilitator dan moderator

d. Masalah menjadi fokus dan sarana untuk mengembangkan keterampilan pemecahan masalah.

e. Informasi-informasi baru dapat diperoleh dari belajar mandiri.

Sedangkan menurut Rusman, karakteristik dari pembelajaran berbasis masalah, antara lain: (1) permasalahan yang digunakan menjadi starting point dalam belajar, merupakan permasalahan yang ada di dunia nyata, membutuhkan perspektif ganda dan menantang pengetahuan yang dimiliki siswa; (2) belajar pengarahan diri; (3) pembelajaran kolaboratif, komunikasi, dan kooperatif; (4) pengembangan

${ }^{12}$ Ibid., 13

13Paulina Pannen, dkk., Kontruktivisme dalam Pembelajaran (Jakarta: Depdiknas, 2001), 23 
keterampilan inquiry dan pemecahan masalah; (5) keterbukaan proses pembelajaran yang meliputi sintesis dan integrasi proses belajar; dan (6) evaluasi dan review pengalaman siswa dan proses belajar. ${ }^{14}$

Menurut Sternberg merancang model pemecahan masalah adalah sebagai berikut: ${ }^{15}$

a. Identifikasi masalah, pengenalan masalah kepada siswa.

b. Pendefinisian masalah dan representasinya, siswa dituntut untuk mendefinisikan masalah dengan tepat dan mempresentasikannya.

b. Perumusan strategi, setelah masalah didefinisikan secara efektif, maka siswa harus menyusun atau merencanakan strategi penyelesaiannya.

c. Pengorganisasian informasi, tahap ini adalah pengumpulan informasi dan membuat struktur informasi serta mengintegrasikannya.

d. Pengolahan sumber daya.

e. Monitoring, memonitor langkahlangkah yang dilakukan untuk mencapai tujuan.

f. Evaluasi, dalam proses penyelesaian, evaluasi merupakan langkah akhir untuk mengukur tercapainya hasil yang sempurna atau tidaknya.

Menurut Arends, penerapan problem based learning terdiri dari 5

\footnotetext{
${ }^{14}$ Rusman, Model-model Pembelajaran (Mengembangkan Profesionalisme Guru) (Jakarta: Raja Grafindo Persada, 2014), 232

${ }^{15}$ Martinis Yamin, Strategi dan Metode dalam Model Inovasi Pembelajaran (Jakarta: Gaung Persada Press Group, 2013), 86
}

fase, fase-fase dimaksud ditunjukkan pada table $1 .{ }^{16}$

Selain itu menurut Amir, di dalam model pembelajaran ini terdapat 6 proses yang akan dilalui oleh siswa yaitu: ${ }^{17}$

a. Mengklarifikasi istilah dan konsep yang belum jelas.

b. Merumuskan masalah.

c. Menganalisi masalah.

d. Menata gagasan secara sistematis dan menganalisisnya.

e. Memformulasikan tujuan pembelajaran.

f. Mencari informasi tambahan dari sumber lain (di luar diskusi kelompok).

\section{INOVASI PEMBELAJARAN PENDIDIKAN AGAMA ISLAM BERBASIS PROBLEM BASED LEARNING}

Kamus Besar Bahasa Indonesia memberi batasan, inovasi sebagai pemasukan atau pengenalan hal-hal yang baru, penemuan baru yang berbeda dari yang sudah ada atau yang sudah dikenal sebelumnya baik berupa gagasan, metode atau alat. ${ }^{18}$ Pembelajaran dalam dunia pendidikan harus dilakukan inovasi karena zaman selalu berkembang.

Pengembangan kreativitas, pola pikir yang inovatif yang diajarkan pada peserta didik seharusnya menjadi bagian tidak terpisahkan dari

16Ibid., 82

${ }^{17}$ M. Taufiq Amir, Inovasi Pendidikan..., 24

${ }^{18}$ W.J.S. Poerwadarminta, Kamus Besar Bahasa Indonesia (Jakarta: Balai Pustaka, 1990), 330 
setiap tujuan mata pelajaran yang diberikan di dalam sebuah lembaga pendidikan, termasuk mata pelajaran Pendidikan Agama Islam (PAI). Membekali para siswa dengan kreativitas, berarti memberi mereka kesempatan yang diperlukan menghadapi kehidupan nyata dan berkembang bukan hanya pada masa kini, tapi juga untuk masa yang akan datang.

Pandangan klasik yang selama ini berkembang adalah bahwa pengetahuan secara utuh dipindahkan dari pikiran guru ke pikiran anak. Penelitian pendidikan sains pada tahun-tahun terakhir telah mengungkapkan bahwa pengetahuan itu dibangun dalam pikiran seseorang. Pandangan terakhir inilah yang dianut oleh konstruktivisme. ${ }^{19}$ Pembelajaran pendidikan agama Islam berbasis problem based learning/PBL ini bisa diterapkan pada semua mata pelajaran termasuk pada pelajaran pendidikan agama Islam. Bukan model pembelajarannya yang sulit, akan tetapi butuh tingkat kreatifitas yang tinggi dari tenaga pendidik yang dalam hal ini guru/dosen. Problem based learning ini seharusnya tidak di aplikasikan secara klasik/konvensional atau berdiri sendiri, akan tetapi bisa dikombinasikan dengan menggunakan berbagai pendekatan, strategi, metode, teknik dan taktik sehingga tujuan pembelajaran bisa tercapai secara efektif dan efisien.

${ }^{19}$ Yatim Riyanto, Paradigma Baru Pembelajaran (Jakarta: Kencana Prenada Media Group, 2012), 144
Khususnya pada mata pelajaran PAI yang biasanya guru hanya monoton menyampaikan dengan menggunakan model ekspositori atau cendurung menggunakan teacher centered dan membuat kejenuhan bagi pendengar. Problem based learning bukanlah hal yang baru dalam dunia pendidikan, akan tetapi baru-baru ini berdasarkan beberapa hasil penelitian, model PBL ini jika diterapkan dengan baik dan dikombinasikan dengan beberapa strategi yang lain, akan mencapai tujuan pembelajaran secara maksimal. Selain itu kelebihannya juga akan memberikan pengalaman tersendri bagi peserta didik, akan terciptanya suasana belajar yang menyenangkan.

\section{KESIMPULAN}

Belajar adalah suatu proses yang dilakukan manusia untuk menambah, memperluas, dan mendalami pengetahuan, nilai, dan sikap serta ketrampilan yang dilakukan secara berulang-ulang untuk medapatkan perubahan yang diinginkan. Pembelajaran pendidikan agama Islam yang ada saat ini kebanyakan masih menggunakan cara yang konvensinal dalam mengajarkannya oleh pendidik kepada peserta didik. Maka salah satu model pembelajaran, yaitu problem based learning ini bisa digunakan sebagai acuan untuk melakukan inovasi untuk meningkatkan standar proses yang ada khususnya untuk pembelajaran Pendidikan Agama Islam. 
Problem based learning memang bukan hal baru dalam dunia pendidikan, akan tetapi semakin berkembangnya zaman, maka model ini juga selalu berkembang menyesuaikan situasi dan kondisi yang ada dan bisa dilakukan inovasi dengan mengkombinasikan dengan pendekatan, strategi, metode, teknik dan taktik yang beragam, maka tingkat kreatifitas seorang pendidik diuji sehingga melahirkan lulusan yang aktif, kreatif, inovatif dan produktif.

\section{REFERENSI}

[1] Amir, M. Taufiq. Inovasi Pendidikan Melalui Problem Based Learning. Jakarta: Kencana, 2009. Cet. Pertama.

[2] Maunah, Binti. Landasan Pendidikan. Yogyakarta: Teras, 2009.

[3] Nurfuadi. Profesionalisme Guru. Purwokerto: STAIN Press, 2012.

[4] Pannen, Paulina, dkk. Kontruktivisme dalam Pembelajaran (Jakarta: Depdiknas, 2001), 23

[5] Peraturan Pemerintah Republik Indonesia Nomor 32 Tabun 2013.

[6] Poerwadarminta, W.J.S. Kamus Besar Bahasa Indonesia. Jakarta: Balai Pustaka, 1990

[7] Riyanto, Yatim. Paradigma Baru Pembelajaran. Jakarta: Kencana Prenada Media Group, 2012.

[8] Rusman. Model-model Pembelajaran (Mengembangkan
Profesionalisme Guru). Jakarta: Raja Grafindo Persada, 2014.

[9] Sanjaya, Wina. Strategi Pembelajaran. Jakarta: Kencana, 2006. Cet. I.

[10] Shoimin, Aris. 68 Model Pembelajaran Inovatif dalam Kurikulum 2013. Yogyakarta: Ar-Ruzz Media, 2014

[11] Sutirman. Media dan Model-Model Pembelajaran Inovatif. Yogyakarta: Graha Ilmu, 2013. Cet. Pertama.

[12] Yamin, Martinis. Strategi dan Metode dalam Model Inovasi Pembelajaran. Jakarta: Gaung Persada Press Group, 2013. 
Tabel 1. Tahap-Tahap Pelaksanaan dalam Problem Based Learning

\section{Tahap Tahap dalam Problem Based Learning}

1. Orientasi siswa pada masalah

2. Mengorganisasi siswa untuk belajar

3. Membimbing penyelidikan individual maupun kelompok

4. Mengembangkan dan menyajikan hasil karya

5. Menganalisis dan mengevaluasi proses pemecahan masalah

\section{Perilaku Guru}

Guru menjelaskan tujuan pembelajaran, menjelaskan logistic yang dibutuhkan, mengajukan fenomena atau demonstrasi atau cerita untuk memunculkan masalah, memotivasi siswa untuk terlibat dalam pemecahan masalah Guru membantu siswa untuk mendefinisikan dan mengorganisasikan tugas belajar yang berhubungan dengan masalah tersebut Guru mendorong siswa untuk mengumpulkan informasi yang sesuai, melaksanakan eksperimen untuk mendapatkan penjelasan dan pemecahan masalah

Guru membantu siswa dalam merencanakan dan menyiapkan karya yang sesuai seperti laporan, video, dan model serta membantu mereka untuk membagi tugas dengan temannya.

Guru membantu siswa untuk melakukan refleksi atau evaluasi terhadap penyelidikan mereka dan proses-proses yang mereka gunakan 